\title{
Design and Development of a Charge Controller for a Photo- Voltaic System
}

\author{
Oti Stephen Ejiofor*, Nnadi Damian Benneth, Ogbuefi Uche, Ugwu Celestine \\ Department of Electrical Engineering, University of Nigeria, Nsukka, Enugu State, Nigeria.
}

*Corresponding Author: Oti Stephen Ejiofor, Department of Electrical Engineering, University of Nigeria, Nsukka, Enugu State, Nigeria.

\begin{abstract}
Inconsistency in power supply has been a serious problem that has been plaguing most developing countries including Nigeria. The unreliability in supply from grid has led to individuals and organizations seeking for alternative sources of power. Electric power from the grid cannot be fully relied on; however it is possible to have them stored in wet cells for future use. The charge controller emerged as the circuit which can be used to feed charges to a cell for storage without tampering with the life span of the cell. Instead of just using the normal rectified d.c to charge our batteries, it is decided that a charge controller circuitry connected to a solar panel be used so that as the intensity of sunlight increases, more charges will be stored in the wet cell for future use. This method seems to be better as it does not rely on supply from the grid. However, there are drawbacks associated with this method as the panel will not be able to feed charges to the battery during night hours when there will be no sunlight, therefore the system is not 100\% efficient. The photo-voltaic charge controller, therefore, should be made to interface between sources from the grid and solar panel as well for a greater reliability percentage. The interface may be done with the help of a relay.
\end{abstract}

Keywords: Charge controller, charging, solar panels, photovoltaic system, indicator, protection.

\section{INTRODUCTION}

Due to the outrageous increase in traditional power failures, there is need for an alternative source of power. This alternative power can be gotten from renewable energies, especially the solar. Photovoltaic solar systems can be divided into two basic categories- grid connected and isolated solar systems. The grid connected systems feed the electricity produced by solar panels to the grid using an inverter. When the electricity is needed during night or periods with little or no sunlight, the energy is taken back from the grid. In isolated systems, the excess electricity is usually stored in batteries during the day and the batteries are used to power the home appliances in times when photovoltaic panels do not produce enough energy [1].

Solar panels can be used to harness energy and generate a portion of home's power in order to reduce the dependence on conventional power sources. The task of the solar panel, however, is incomplete without the charge controller as systems with energy storage need a way to regulate the flow of energy into a battery.

A charge controller or charge regulator is basically a voltage and/or current regulator that helps to keep batteries from overcharging. It regulates the voltage and current coming from the solar panels going to the battery banks. Most $12 \mathrm{~V}$ panels give an output of about $15-20 \mathrm{~V}$, if there is no form of regulation, the batteries will be damaged from overcharging [1,2].

One of the best ways to get power to remote, off-grid locations in Nigeria, is through Solar Home System (SHS). This system consists of photovoltaic panel, battery and a solar charge controller. Solar energy is stored in batteries. Energy storage is growing and advancing, causing charge controllers to become more prevalent; hence, charge controlling is a prerequisite to storing surplus energy in batteries. The charge controller conditions the DC electrical voltage and current produced by the $\mathrm{PV} /$ solar panel array to charge a battery. The battery stores the DC electrical energy so that it can be used when there is no solar energy available. DC loads can be powered directly from the PV/solar panel/battery. The inverter converts the DC power stored in the battery into AC power to enable powering of AC loads [3]. 


\section{Photovoltaic Charge Controller}

A charge controller (or charge regulator) is basically a voltage and/or current regulator to keep batteries from overcharging. It regulates the voltage and current coming from the solar panels and going to the battery. Most $12 \mathrm{~V}$ panels produce about 17 to 20volts, so if there is no regulation, the batteries will be damaged from overcharging. The primary function of a charge controller is to maintain the battery at highest possible state of charge. It protects the battery from overcharge and disconnects the load to prevent deep discharge. Ideally, charge controller directly controls the state of the battery. It checks the state of charge of the battery between pulses and adjusts itself each time. This technique e allows the current to be effectively "tapered" and the result is equivalent to constant voltage charging [4]. Without the charge controller, the current from the PV module will flow into a battery proportional to the irradiance, whether the battery needs to be charging or not. If the battery is fully charged, unregulated charging will cause the battery voltage to reach exceedingly high levels, causing severe gassing, electrolyte loss, internal heating and accelerated grid corrosion. Therefore, charge controllers maintain the potency and extend the lifetime of the battery.

\subsection{Types of PV Charge Controllers}

There are two types of charge controllers mostly used in solar power systems, these are; the Pulse Width Modulation (PWM) and Maximum Power Point Tracking (MPPT) charge controllers. Both adjust charging rates depending on the battery's capacity as well as monitor the battery temperature to prevent overheating.

\subsubsection{PWM Charge Controllers}

The Pulse Width Modulation charge controller emits pulses of electricity to the battery in varying lengths. At the end of each pulse, the charge controller briefly switches OFF to measure the battery capacity and adjust its output values to match. It essentially acts as an intelligent switch between batteries and the solar panels that controls the voltage and current flowing into the batteries. Nominal $12 \mathrm{~V}$ lead acid battery voltages may range from around $11 \mathrm{~V}$ when empty to over $14 \mathrm{~V}$ when charging. It is the task of the charge controller to take $17-19 \mathrm{~V}$ from a solar panel and safely feed that to the batteries $[4,5]$.

PWM charge controllers have the following advantages:(i) Higher charging efficiency (ii) Longer battery life (iii) Reduced battery over heating (iv)Minimizes stress on the battery and (v) Ability to de-sulfate a battery. A PWM controller is not a DC to DC transformer. The PWM controller is a switch which connects the solar panel to the battery. When the switch is closed, the panel and the battery will be at nearly the same voltage. Assuming a discharged battery, the initial charge voltage will be around $13 \mathrm{~V}$, and assuming a voltage loss of $0.5 \mathrm{~V}$ over the cabling plus controller, the panel will be at Vpwm $=13.5 \mathrm{~V}$. The voltage will slowly increase with increasing state of charge of the battery. When absorption voltage is reached, the PWM controller will start to disconnect and reconnect the panel to prevent overcharge.

\subsubsection{MPPT Charge Controllers}

An MPPT charge controller is that which is embedded with the MPPT algorithm to maximize the amount of current going into the battery from PV module. The MPPT charge controller is a DC to DC converter which operates by taking DC input from PV module, changing it to AC and converting it back to a different DC voltage and current to exactly match the PV module to the battery. MPPT solar charge controllers are useful for off-grid solar power systems such as stand-alone solar power system, solar home system and solar water pump system [5].

It extracts the maximum available power from PV module by making them operate at the most efficient voltage, that is, it checks output of PV module, compares it to battery voltage then fixes what is the best power that PV module can produce to charge the battery and converts it to the best voltage to get maximum current into battery. It can also supply power to a DC load, which is connected directly to the battery. MPPT is most effective when the weather is cold, cloudy or hazy and when the battery is highly discharged. They would be no negative repercussions from using an MPPT controller on a solar panel with a voltage close to the battery voltage, but the benefits from MPPT in this sort of system would be much lower [6]. 


\subsection{Charging Cycle of Charge Controller}

Most quality charge controller units operate on a 3-stage charging cycle as follows:

- Bulk stage: In this stage, the charge controller is directly connecting the solar panels to the batteries. The solar panel voltage is drawn down to match the battery voltage and the full current output of the solar panels is dumped into the batteries. The value of this current will be equal to the short circuit current $\mathrm{I}_{\mathrm{sc}}$ of the solar array. This stage will contribute the majority of the charge to the batteries and is sometimes called the constant-current stage. As the battery gets charged, its voltage slowly increases until it reaches around $14.4 \mathrm{~V}$. At this point the batteries will be around $80 \%$ charged, however continued charging at this voltage and maximum current could be damaging, so the charge controller moves into the next stage.

- Absorption stage: The charge controller slowly tops up the remaining charge. It does this by maintaining a constant voltage of around $14.4 \mathrm{~V}$, but slowly limiting the current flow to the battery. This allows the chemical reactions occurring inside the battery to progress at a safe rate and prevents over-heating and over-gassing. The current will taper off to safe levels as the battery becomes more fully charged. Once the battery is nearly full, the charge controller switches to the Float stage.

- Float stage: When the battery is fully recharged, there can be no more chemical reactions and all the charging current is turned into heat and gassing. The purpose of float is to protect the battery from long-term overcharge. This is a 'trickle-charge' mode with just a trickle of current and a constant voltage of around $13.8 \mathrm{~V}$. The battery can be safely maintained here at $100 \%$ capacity for long periods of time while the small power input offsets the natural discharge rate of the battery $[7,10]$.

\subsection{Choosing a Charge Controller}

One has to limit one's choices to controllers that work with your battery bank voltage rating, which will usually be 12,24 , or $48 \mathrm{~V}$. Then, calculate the approximate maximum ampere rage your controller will need to handle. Divide the PV array watts by the system voltage to get ampere rage, then add a $25 \%$ safety margin to account for higher irradiance conditions. For example, a 40A rated controller could possibly handle $480 \mathrm{~W}$ of PV into a $12 \mathrm{~V}$ battery bank; $960 \mathrm{~W}$ into a $24 \mathrm{~V}$ bank; and $1,920 \mathrm{~W}$ into a $48 \mathrm{~V}$ bank. After factoring in the additional $25 \%$, those maximum ratings become $384 \mathrm{~W}, 768 \mathrm{~W}$, and $1,536 \mathrm{~W}$ respectively [8].

Be sure to carefully check the charge controller manufacturer's specifications for the maximum recommended array power rating for different battery bank voltages. In the comparison table, maximum amperage is shown for $12 \mathrm{~V}$ battery bank charging, as some controllers have different maximum amperage ratings at different system voltages.

Next, decide on a PV array voltage. If you go with a non-MPPT controller, the nominal array voltage must match your nominal battery voltage. If you use a MPPT controller, many manufacturers have a spreadsheet or online calculator pre-loaded with the specifications for many popular PV modules. The calculator will also consider the temperature versus voltage performance of your modules, needed to protect the controller from elevated voltage during cold weather. If there are no string-sizing calculator available, you will need to use the PV module manufacturer's specifications sheet to determine how high the module voltage could go during cold weather $[9,11]$.

\section{BLOCK DIAGRAM}

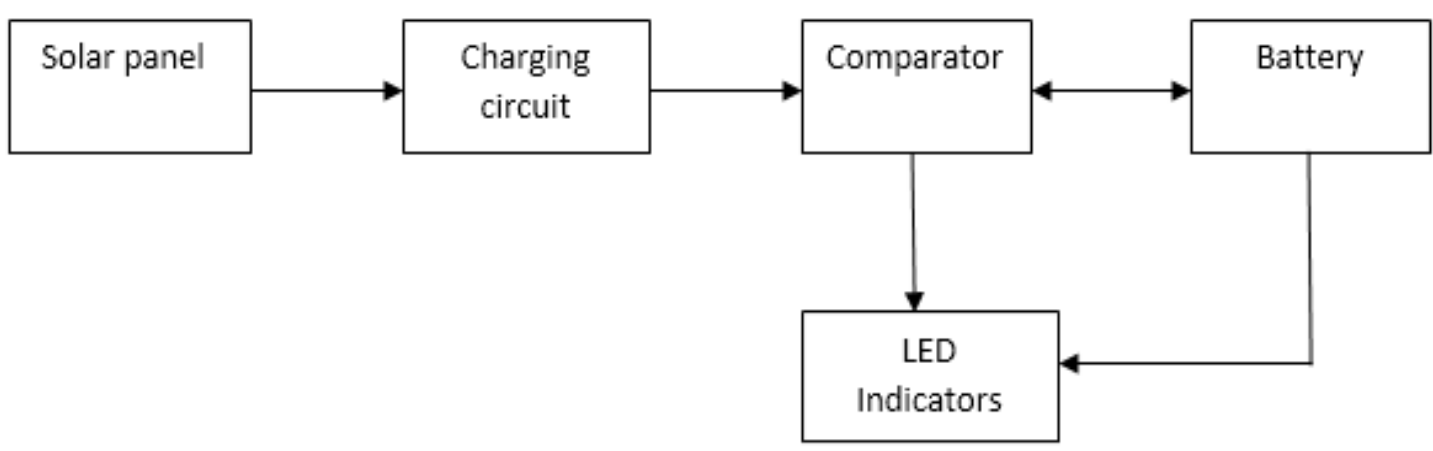

Fig1. The block diagram for PV charge controller. 
Solar Panel: The solar panel is installed outside the building usually at roof tops where it can trap maximum energy direct from sunlight. Due to its configuration, heat energy from the sun is converted into DC voltage to be used by the charge controller.

Charging Circuit: This block is made up of a voltage regulator (LM 338 IC) configured in such a way as to receive input from the solar panel and feed the charges at a constant rate to the battery.

Comparator block: This block is usually made up of diodes connected in a manner as to compare the battery voltage level and the charging voltage while still charging the battery. When battery is fully charged, with the aid of this block, it is cut off from supply and it triggers an LED to indicate that it has been fully charged.

Battery block: This is made up of a set of rechargeable batteries configured in a way as to store the charges fed to it. It also has a feedback to the LED block to indicate when it is charging. When the battery gets full, current from it tends to flow back to the comparator, causing the comparator to cutoff the charging current and trigger a red LED to indicate that the battery is fully charged.

\subsection{The PV Charge Controller Circuit Diagram}

The circuit as shown below was first implemented on a bread board before soldering the components on to the vero board.

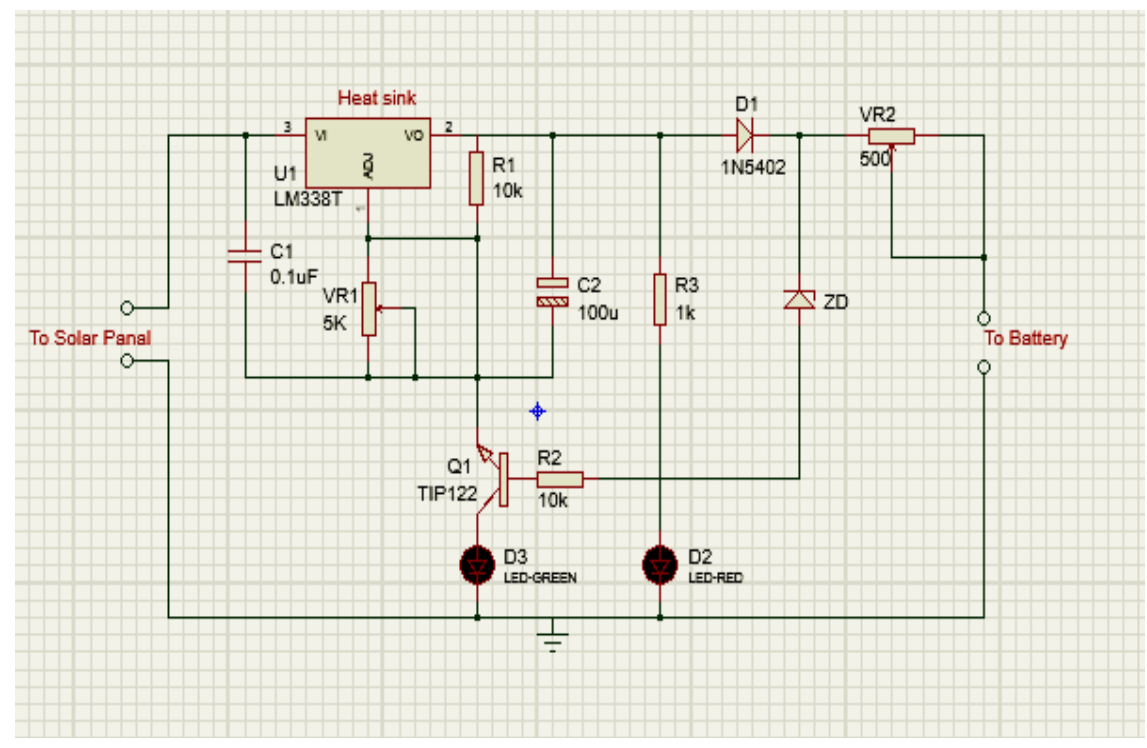

Fig2. Circuit diagram for the PV charge controller.

An unregulated power produced through the action of the solar panel travels to the charge controller. This unregulated DC voltage is now applied to the LM338 variable voltage regulator to provide regulated DC voltage. The output voltage of this voltage regulator is variable from $1.2 \mathrm{~V}$ to $32 \mathrm{~V}$ and the maximum output current from this IC is 7A. The output voltage of this voltage regulator is varied by varying the pot $5 \mathrm{k}$ which is connected to the adjust pin of LM338. The LM338 voltage regulator output is applied to the battery through the diode D1 and variable resistor (VR2). Here diode D1 is used to avoid the discharge of battery when main supply fails. When battery charges fully, the zener diode (ZD) which is connected in reverse bias conducts. Now the base of TIP 122 NPN transistor gets the current through the zener so that the total current is grounded. In this circuit, green LED is used for indicating the charging of the battery. Resistor R3 is used to protect the green LED from high voltages.

\subsection{Working Principle}

If the battery voltage is below $12 \mathrm{~V}$, then the current from LM338 IC flows through the variable resistor (VR2) and diode D1 to the battery. At this time zener diode (ZD) will not conduct because battery takes all the current for charging. When the battery voltage rises to $12.5 \mathrm{~V}$, the current flow to the battery stops and zener diode gets the sufficient breakdown voltage and it allows the current through it. Now the base of the transistor gets the sufficient current to turn on so that the output current from LM338 voltage regulator is grounded through the transistor Q1. As a result, Red LED indicates the full charge status. 


\subsection{Component Selection for Controller Design}

- Solar Panel: This is the power supply; it is responsible for charging the battery. It has the following specifications:

i) $\mathrm{V}_{\mathrm{oc}}=22.05 \mathrm{~V}$

ii) $\mathrm{I}_{\mathrm{sc}}=1.92 \mathrm{~A}$

iii) $\mathrm{I}_{\mathrm{mp}}=1.71 \mathrm{~A}$

iv) $\mathrm{V}_{\mathrm{mp}}=17.5 \mathrm{~V}$

v) Max. Power $=30 \mathrm{~W}$

- LM338: It is an adjustable voltage regulator IC; which means it provides Line Regulation (irrespective of the changes in the input voltage, the output voltage remains constant) and Load Regulation (irrespective of the changes in load the output voltage is fixed). We can adjust the output voltage by varying the resistance across the adjust pin. This is needed to have a fixed voltage across the battery (to limit the current and charge it at constant voltage). Directly connecting the solar panel to the battery may even explode it due to the varying output from it. The voltage across $\mathrm{R} 1$ is maintained to be $1.25 \mathrm{~V}$ using an internal circuit. The $\mathrm{V}_{\text {out }}$ is then obtained to be constant and given by: $\mathrm{V}_{\text {out }}=\mathrm{V}_{\mathrm{R} 1} *\left(1+\frac{R 2}{R 1}\right)+\mathrm{I}_{\text {adj }} * \mathrm{R}_{2}$. This $\mathrm{I}_{\text {adj }}$ is of the order of $\mu \mathrm{A}$ so can be neglected to have a regulated output voltage.

- Battery: This circuit is designed to charge $12 \mathrm{~V}$ sealed lead-acid batteries at a maximum current of 7A. This means that for any battery connected to the device, a maximum current of $7 \mathrm{~A}$ will flow to the battery. Lead acid batteries are not the best available options in rechargeable batteries (unlike portable and easy to use Li-ion batteries). But for small applications like our solar lamp, they are good enough. Care must be taken while handling acid batteries.

- Diodes (1N5402): These are simply blocking diodes which ensure that the current flows only in one way so that the battery does not discharge when the output from solar panel is low.

- Zener Diode and the Transistor (TIP122): This part of circuit ensures that once the charging cut off voltage is reached by the battery, the charging stops. The Zener is rated at $12 \mathrm{~V}$ as breakdown. This allows all the voltage to drop across the Zener and the transistor switches on due to biasing of the Base-Emitter junction. The transistor acts like a switch and once the battery is charged, it draws all the current thus protecting the battery.

- $\quad$ are used to indicate charging condition.

Impedance of battery charger, $\mathrm{Z}_{\mathrm{out}}=\mathrm{R}_{\mathrm{s}} *\left(1+\frac{R 1}{R 2}\right)$

Where: $\mathrm{R}_{1}=240$ ohms; $\mathrm{R}_{2}=5000$ ohms; $\mathrm{R}_{\mathrm{s}}=1 \mathrm{ohm}$

Hence, $Z_{\text {out }}=1 *\left(1+\frac{240}{5000}\right)=1.048 \mathrm{ohms}$

Note: The $0.1 \mu \mathrm{f}$ capacitor is recommended for filtering output transients

3.4. Materials Used

\begin{tabular}{|l|l|l|l|}
\hline S/N & ITEM & VALUE & QUANTITY \\
\hline 1 & Heat Sink & & 2 \\
\hline 2 & Polar capacitor & $0.1 \mu \mathrm{F} / 50 \mathrm{~V}$ & 1 \\
\hline 3 & Variable resistor & $5 \mathrm{k} \Omega$ & 1 \\
\hline 4 & Resistor & $120 \Omega$ & 1 \\
\hline 5 & 1N5402 Diode & & 1 \\
\hline 6 & Zener Diode & & 1 \\
\hline 7 & Resistor & $2 \mathrm{k} \Omega$ & 2 \\
\hline 8 & TIP 122 Transistor & & 1 \\
\hline 9 & LED & & 2 \\
\hline 10 & Variable resistor & $\mathbf{5 0 0} \Omega$ & 1 \\
\hline
\end{tabular}

International Journal of Innovative Research in Electronics and Communications (IJIREC) 


\section{Determination of Solar PANEL Behavior at DifFERENT Light InTENSITIES.}

The following test conditions are adduced.

\begin{tabular}{|l|l|}
\hline Conditions & Open circuit voltage across the panel \\
\hline Covered with cardboard & $0.263 \mathrm{~V}$ \\
\hline Facing the desk & $0.468 \mathrm{~V}$ \\
\hline At the window $(11 \mathrm{am})$ & $2.5 \mathrm{~V}$ \\
\hline In the lab & $7.62 \mathrm{~V}$ \\
\hline At the desk & $5.2 \mathrm{~V}$ \\
\hline Using a torchlight at distance $15 \mathrm{~cm}$ & $11.22 \mathrm{~V}$ \\
\hline At the terrace $(2 \mathrm{pm})$ & $21.22 \mathrm{~V}$ \\
\hline Covered with paper & $0.63 \mathrm{~V}$ \\
\hline
\end{tabular}

Observations: Solar panels are heavily dependent on the intensity and the nature of light falling on them to produce any kind of voltage. The output varies right from $0.2 \mathrm{~V}$ to $21.2 \mathrm{~V}$.

Result: Sunlight matters a lot. So to make the best out of a fixed solar panel, There is need to have some kind of power tracking which will always allow the panel to produce a maximum power by impedance matching (external resistor across the cell).

\subsection{Determination of IC LM338 Working Using Power Supply}

Conditions: $R_{1}=180 \Omega ; R_{2}=500 \Omega$

\begin{tabular}{|l|l|l|l|l|l|}
\hline $\mathbf{V}_{\text {in }}(\mathbf{V})$ & $\mathbf{V}_{\text {ref }}(\mathbf{V})$ & $\mathbf{V}_{\text {out }}(\mathbf{V})$ & $\mathbf{V}_{\text {in }}-\mathbf{V}_{\text {out }}(\mathbf{V})$ & $\mathbf{I}_{\text {ref }}(\mathbf{m A})$ & $\mathbf{I}_{\text {adj }}(\boldsymbol{\mu A})$ \\
\hline 6.85 & 1.225 & 4.64 & 2.12 & 6.81 & 19 \\
\hline 8.30 & 1.225 & 4.657 & 3.67 & 6.815 & 53 \\
\hline 10.59 & 1.224 & 4.65 & 4.65 & 6.815 & 46.6 \\
\hline 12.16 & 1.225 & 4.667 & 4.66 & 6.81 & 73 \\
\hline 15.68 & 1.225 & 4.68 & 11.00 & 6.81 & 99 \\
\hline 23.67 & 1.225 & 4.651 & 18.19 & 6.817 & 41 \\
\hline
\end{tabular}

\subsection{Determination of IC LM338 Working Using Solar Panel}

Conditions: $R 1=180 \Omega, R 2=500 \Omega$

\begin{tabular}{|l|l|l|l|l|}
\hline $\mathbf{V}_{\text {in }}(\mathbf{V})$ & $\mathbf{V}_{\text {ref }}(\mathbf{V})$ & $\mathbf{V}_{\text {out }}(\mathbf{V})$ & $\mathbf{I}_{\text {ref }}(\mathbf{m A})$ & $\mathbf{I}_{\text {adj }}(\boldsymbol{\mu A} \mathbf{A})$ \\
\hline 4.85 & 1.225 & 4.64 & 6.81 & 19 \\
\hline 6.30 & 1.225 & 4.654 & 6.815 & 53 \\
\hline 7.59 & 1.224 & 4.65 & 6.815 & 46.6 \\
\hline 8.16 & 1.225 & 4.66 & 6.81 & 73 \\
\hline 10.68 & 1.225 & 4.68 & 6.81 & 99 \\
\hline 11.67 & 1.225 & 4.651 & 6.817 & 41 \\
\hline
\end{tabular}

Observations: The output voltage from the IC is observed to be nearly constant with the input-output differential voltage ranging from $2.1 \mathrm{~V}$ to $20 \mathrm{~V}$ (Power supply limit).

Results: IC LM 338 gives a regulated output for a particular range of input voltage.

\subsection{To Study the Working of Zener Diodes}

Setup: The Zener is tested for its rating using a power supply, LED and a resistor. The Zener conducts only after the voltage across it is greater than $12.78 \mathrm{~V}$ (i.e. reverse breakdown voltage). This is easily seen when the LED lights up.

Observations: (Series resistor: $1 \mathrm{k} \Omega$ )

\begin{tabular}{|l|l|l|}
\hline $\mathbf{V}_{\text {in }}(\mathbf{V})$ & $\mathbf{V}_{\text {zener }}(\mathbf{V})$ & LED status \\
\hline 1 & 0.3 & OFF \\
\hline 10.2 & 6.77 & OFF \\
\hline 12.1 & 7.23 & OFF \\
\hline 13.2 & 12.55 & ON \\
\hline 14.2 & 12.55 & ON \\
\hline
\end{tabular}

\subsection{To Study the Discharging of a $12 \mathrm{~V}$ Battery}

Setup: the sealed lead acid battery available is fully charged with voltage across it as $12.39 \mathrm{~V}$. We need to discharge it to at least $10.8 \mathrm{~V}$ so as to charge it using our solar charger circuit. Thus, an emergency lamp was used to discharge the battery as fast as possible. Battery discharging depends on the capacity of the battery and the current drawn through it. 


\section{Observations:}

\begin{tabular}{|l|l|}
\hline Time (min) & Voltage $(\mathbf{V})$ \\
\hline 0 & 12.17 \\
\hline 15 & 12.146 \\
\hline 30 & 12.120 \\
\hline 45 & 12.099 \\
\hline 60 & 12.082 \\
\hline 120 & 11.981 \\
\hline 150 & 11.89 \\
\hline
\end{tabular}

\section{CONCLUSION}

It is possible to charge batteries with normal rectified direct current from an AC source. This method is however dangerous to the battery life span as the charging current may be varying even above the battery rating. The essence of charge controllers, therefore, is to limit the charging current of a battery to its normal rating, and also to cut-off the charging current when the battery gets full, else the battery will swell-up.

Solar panels are as good as power supplies of an average of $12 \mathrm{~V}$ in bright sunlight. The only problem is unregulated voltage due to variation in intensity of light. IC LM 338 solves the problem by regulating the output voltage but again there is a voltage drop across it which makes the system less efficient. PV system charger circuits need voltage regulators so as to charge the batteries at constant voltage.

The battery charging process should be stopped once it is fully charged and this is ensured using a zener diode which will start conducting at the cut off voltage. The control of battery charging is so important that most manufacturers of high quality batteries specify the requirements for voltage regulation, low voltage disconnect and temperature compensation. When these limits are not respected, it is common for batteries to fail after less than one quarter of their normal life expectancy, regardless of their quality or cost. A good charge controller is relatively charger compared to the total cost of a power system.

This work has produced a low cost, reliable and functional solar charger using locally sourced and available components. The product worked satisfactorily and can be used for domestic purposes to solve problems of power supply in Nigeria.

\section{RECOMMENDATION}

Solar energy is a clean energy source and it is high time we understood its importance and embrace it as an alternative supply of energy. In the circuit for this project, Solar panels were used as a means to trap energy from the sun and fed into a voltage regulator so as to have a constant voltage charging for the battery. Batteries are the easiest way to store energy.

Hence, PV charger circuits aim at charging batteries rather than driving components. Rechargeable batteries like Lead Acid, Li-ion and NiMH are used depending on the requirements of the user. Here, I used sealed Lead Acid ones. It is also very necessary to cut-off charging once the battery is fully charged. This is managed using a zener diode which switches on at the cut-off voltage and diverts the current through the transistor.

The battery is thus charged at constant voltage and at desired rating depending on the amount of current supplied. Solar energy is the most abundant but least used source of energy. But the fact remains that it is the solution to most of our problems. The major challenges we face in going solar is expensive technology, limited space and energy. We need to address them by having more efficient materials and most importantly awareness among people so that they can maximize the potential.

\section{REFERENCES}

[1] Korenčiak P., Fiedler P. "Charge Controller for Solar Panel Based Charging of Lead Acid Batteries, Faculty of Electrical Engineering and Communication, Department of Control and Instrumentation, 2011, Brno University of Technology pp. 11.

[2] https://www.solar-electric.com/learning-center/batteries-and-charging/solar-charge controller-basics.html

[3] https://www.solarpowerworldonline.com/2015/07/what-is-a-charge-controller's-function 
[4] https://en.m.wikipedia.org/wiki/pulse-width-modulation

[5] https://www.zebra.energy/blog/how-do-PWM-charge-controllers-work

[6] Ishtiak A. K., Abid A. S., Navid A. M., Irin P. S., Saha S. "Design of A Solar Charge Controller for a 100WP Solar PV System" International Journal of Engineering Research \&Technology (IJERT) Vol. 2 Issue 11, November 2013, pp. 1.

[7] https://www.photonicuniverse.com/en/how-to-choose/solar-charge-controller

[8] https://www.enerdrive.com.au/mppt-vs-pwm-solar-controllers

[9] James P., Dunlop P. E. "Batteries and Charge Controller in Stand-Alone Photovoltaic systems fundamentals and applications". Florida Solar Energy Centre, University of Central Florida, 1997, pp. 24, 28.

[10] Mohammed S. I. "Low Cost Solar Charge Controller", Lambert Academic publishing. 2012, pp. 10-15.

[11] Noor J. \& Ayuni B. M. "Photovoltaic Charge Controller, University of Malaysia, Pahang, Malaysia", 2009, pp. 4, 5.

Citation: Oti Stephen Ejiofor, et.al, (2019) "Design and Development of a Charge Controller for a PhotoVoltaic System”, International Journal of Innovative Research in Electronics and Communications (IJIREC), 6(3), pp 1-8. DOI: http://dx.doi. org/10.20431/2349-4050.0603001

Copyright: (C) 2019 Authors, This is an open-access article distributed under the terms of the Creative Commons Attribution License, which permits unrestricted use, distribution, and reproduction in any medium, provided the original author and source are credited. 